\title{
OS CONSELHOS ESCOLARES NO ENSINO FUNDAMENTAL: ANÁLISE DA PERCEPÇÃO SOBRE A PARTICIPAÇÃO NA GESTÃO ESCOLAR
}

\section{THE SCHOOL COUNCILS IN MANAGING ELEMENTARY SCHOOLS: ANALYSIS OF PERCEPTION ON PARTICIPATION IN SCHOOL MANAGEMENT}

\author{
Lydia Maria Pinto Brito ${ }^{1}$ \\ Regina Lúcia Maciel de Sousa ${ }^{2}$ \\ Fernanda Fernandes Gurgel ${ }^{3}$
}

\section{RESUMO}

O estudo objetivou analisar a percepção da participação dos Conselhos Escolares na gestão de escolas do Ensino Fundamental Municipal de Natal. Tratou-se de um estudo de caso, com abordagem quantitativa. Utilizou-se um questionário adaptado de Holanda e Brito (2009), com questões fechadas. A amostra foi definida pelo critério de tipicidade, ou intencional. Foram coletadas 1.170 informações de 90 membros dos Conselhos Escolares representantes dos segmentos Diretores, Professores, Técnicos, Pais e Mães. A teoria de suporte do estudo é a Teoria da Participação. Os autores que sustentam a base teórica são, principalmente, Ammann (1977) e Bordenave (2008). O cotejamento da participação permitiu as seguintes considerações: a percepção de participação na gestão, nos graus mais elevados, acontece, principalmente, na avaliação dos Gestores, Professores e Técnicos. Pais/Mães e Alunos se percebem em graus menos elevados, evidenciando uma diferença relevante ao se comparar a percepção de participação entre os segmentos administrativos e comunidade, o que sugere a necessidade de estratégias que possibilitem a participação de todos no que se refere ao planejamento, execução e usufruto dos bens produzidos pela escola, rumo à consolidação de uma gestão efetivamente participativa, em que os Conselhos Escolares representam parte desse processo.

Palavras-Chave: Gestão Participativa - Participação - Conselho Escolar.

\section{ABSTRACT}

The study aimed at analyzing the perception of the degree of participation of School Councils in managing Elementary Schools in Natal city network. This is a case study with a quantitative approach, in which Holanda and Brito's (2007) structured questionnaire was used, with closed questions. The sample was defined by the criteria of typicality, or intentional. At the end, 1,170 observations were collected from 90 members of school councils' representatives of segments Managers, Teachers, Technicians, Fathers and Mothers. The support study theory is the theory of participation, whose authors argue that the theoretical basis are mainly Bordenave (2008) and Amman (1997). The readback of participation, mediated by the analysis made possible via theoretical base allows the following considerations: The perception of 
participation in higher degrees in school management occurs primarily in evaluating the segments Managers, Teachers and Technicians. Fathers/Mothers and Students share the vision that such participation happens in lower degrees, showing a significant difference when comparing the participation in managing the administrative and community segments, suggesting the need for strategies and tools that enable the participation of all in higher degrees, both with regard to planning, the implementation and usufruct of the goods produced by the school, towards the consolidation of an effective participatory management in which the School Councils represent part of that process.

Keywords: Participatory Management - Participation - School Council.

\section{INTRODUÇÃO}

Numa perspectiva participativa, a gestão escolar tem como finalidade principal o envolvimento, o comprometimento e a participação das pessoas, gerando, assim, a descentralização dos processos de decisão e, consequentemente, a divisão de responsabilidades e o compromisso com resultados, o que, certamente, influenciará diretamente nos processos de ensino e aprendizagem, contribuindo, desta forma, para a promoção de uma educação de qualidade.

Em relação à realidade brasileira os documentos que norteiam a política educacional para as redes municipais de ensino evidenciam a gestão participativa como sendo estratégica para a superação do modelo de gestão autoritária e das desigualdades sociais. Diante disto, torna-se necessário reavaliar os mecanismos autoritários que se estabeleceram nas instituições de ensino municipal, em busca de uma maior participação no espaço escolar.

Neste cenário, a organização das escolas públicas passou por modificações, evidenciando a necessidade de uma efetiva participação dos vários segmentos da comunidade escolar, de modo que essa comunidade possa não só compreender, mas também se sentir parte integrante nos processos de decisão da escola, contribuindo para elevar a qualidade das ações realizadas e dos serviços oferecidos à sociedade, assim como para a motivação e a satisfação dos seus servidores.

Partindo desta premissa, esta pesquisa teve como objetivo geral analisar a percepção dos membros dos Conselhos Escolares das Escolas 
Públicas da rede municipal de Natal sobre o grau de participação nas atividades de planejamento, execução e usufruto na gestão da escola. Consiste em um estudo de caso, com abordagem quantitativa e com finalidade descritiva.

\section{REFERENCIAL TEÓRICO}

A palavra participação, apesar de muito usada, corre o risco de perder a sua essência, antes mesmo que sua contribuição fundamental para a verdadeira democracia seja compreendida e empregada pela sociedade. (BORDENAVE, 2008).

Democracia e participação são dois termos inseparáveis, à medida que um conceito remete ao outro. No entanto, essa reciprocidade nem sempre ocorre na prática "porque, embora a democracia seja irrealizável sem participação, é possível observar a ocorrência de participação sem espírito democrático. Neste caso, o que se teria seria um significado limitado e incompleto de participação". (LUCK, 2009, p. 54).

Para Faria (2009, p. 79) a participação precisa ser vista "em termos de questões técnicas, organizacionais, econômicas, jurídico-político e ideológicas". Para o autor, existem três níveis interdependentes de controle: o econômico, que diz respeito às relações de produção e aos processos de trabalho no que se refere à propriedade e à posse; o político-ideológico, referente à superestrutura construída a partir das relações de produção e de todo o aparato normativo; e o psicossocial, que foca às relações entre os sujeitos, sejam estes individuais ou coletivos, inserido nos processos produtivos e políticos (FARIA, 2009). Deste modo, a participação compreende todas as formas e meios pelos quais os membros de uma organização, como indivíduos ou coletividade, podem influenciar os destinos de uma organização (MOTTA, 1999).

Porém, Lück (2009, p. 95), enfatiza que

Como processo social de construção compartilhada, a autonomia envolve pessoas com interesses vários, assim como múltiplos fatores dicotômicos interatuantes, de que resulta uma certa tensão e até mesmo situações de conflito. Portanto, não pode deixar de ser um processo contraditório, demandando do gestor habilidades especiais. 
Deste modo, torna-se importante salientar que o gestor pode ser considerado como impulsor fundamental do processo participativo, constituindo-se em um dos pilares fundamentais do cotidiano das organizações, promovendo a integração, que seria a complementação entre a capacidade em motivar e a crença dos indivíduos em torno do que a instituição pode oferecer para satisfazer suas necessidades. Observa-se, neste cenário, a importância do desenvolvimento do processo motivacional como um elementochave de uma gestão estratégica e de resultados.

No que se refere a desafios enfrentados com sucesso por muitas organizações pode-se observar que há sempre um elemento comum: a gestão participativa que tem se tornado um diferencial para as organizações que a implementam. Torna-se importante ressaltar que as principais dificuldades encontradas durante a implantação deste paradigma de gestão são principalmente as de origem cultural. Johann (1996) afirma que a participação é um exercício infinitamente mais complexo na prática do que aparenta, da mesma maneira que o exercício da democracia é tão mais trabalhoso do que a ditadura.

Sá (2004) entende que as famílias dos alunos desejam participar da escola, querendo, ao menos, ter mais e melhores informações sobre o andamento pedagógico e o desenvolvimento dos alunos, que também desejam as famílias mais próximas da escola. Segundo o autor, os dirigentes escolares e professores, por seu turno, dizem compartilhar dessas concepções. Nesse sentido, Souza (2006) afirma existir um problema maior: a compreensão do que é participar, do que significa ser parte da escola ou do processo educativo, e questiona até que ponto a participação dos pais e alunos na definição e avaliação dos rumos da escola é, realmente, bem aceita pelos professores e dirigentes.

Pinto e Costa (2009) afirmam que a implementação do modelo participativo é um processo lento, onde estão envolvidas a autonomia, a disciplina, a força de vontade, a colaboração e a união de todos. É importante ressaltar que a participação não se dá somente nas decisões e na participação dos lucros, mas principalmente na responsabilidade por seu próprio comportamento e desempenho, como por exemplo, na Autogestão, 
considerado, na escala de Bordenave (2008), o mais alto grau de participação, em que o grupo tem autonomia para determinar seus objetivos, os meios de controles, e administradores e administrados eliminam suas distâncias e diferenças; ou ainda na Cogestão na qual a administração da organização é compartilhada por um colegiado.

Na sociedade brasileira, a escola pública tem como função social formar o cidadão, através da construção do conhecimento, das atitudes e valores que tornem o estudante crítico, ético, solidário e participativo. É indispensável, para tanto, socializar o saber sistematizado, historicamente acumulado, como patrimônio universal da humanidade, fazendo com que esse saber seja criticamente apropriado pelos indivíduos, que já trazem consigo o saber popular da comunidade em que vivem e atuam. A apropriação desses saberes representam, de fato, um elemento determinante para o processo de democratização da própria sociedade. Deste modo, a contribuição da escola para a democratização da sociedade e para o exercício da democracia participativa fundamenta e exige a gestão escolar democrática. Nesse sentido,

\begin{abstract}
a forma de escolha dos dirigentes, a organização dos Conselhos Escolares e de toda a comunidade escolar para participar e fazer valer os seus direitos e deveres, democraticamente discutidos e definidos, é um exercício de democracia participativa. Assim a escola pública contribuirá efetivamente para afirmar os interesses coletivos e construir um Brasil como um país de todos, com igualdade, humanidade e justiça social. (BRASIL, PNFCE, 2006, p. 06).
\end{abstract}

Pode-se observar que há uma inquietação coletiva para que o sistema de ensino atinja a equidade e a qualidade desejada, sabendo-se, contudo, que existe um longo caminho a percorrer para que se alcance o ideal almejado, que só se realizará quando se efetivar a gestão participativa nas escolas, pois como afirma Cury (2002, p. 171): "a gestão democrática só o é mediante a prática que articule a participação de todos, o desempenho administrativo-pedagógico e o compromisso sociopolítico". Segundo o autor (2002, p. 173), o exercício da gestão democrática é um ato de cidadania: "tratase, pois, da ponte entre o indivíduo e um colegiado, entre a tomada de decisão e a participação em cujas bases encontra-se o diálogo como método e como fundamento" Porém, o sucesso dos órgãos colegiados está diretamente associado à transparência, à agilidade e à confiabilidade das ações 
executadas, assim como ao acesso de seus membros às informações, permitindo elas cheguem a todos os participantes, possibilitando que as decisões de interesse comum sejam tomadas de forma consciente e participativa. Neste contexto, a função do Conselho Escolar se constitui em focar o olhar no Planejamento, na Execução e Avaliação das ações da escola, em um processo de acompanhamento permanente, representando, portanto, um instrumento potencial de participação e exercício da democracia porque sua representatividade é formada por diferentes atores do ambiente escolar e da comunidade. Ammann (1977, p. 81) afirma que "Participar não é só produzir, gerir. Participar é também usufruir dos bens e serviços gerados pela sociedade".

Para Bordenave (2008, p.30) o grau de controle dos membros sobre as decisões é a principal questão-chave na participação em um grupo ou organização. O autor (2008, p. 33) demonstra, no Figura 1, alguns dos Graus de Participação que uma organização pode alcançar, do ponto de vista do menor ou maior acesso ao controle das decisões pelos membros das organizações:

Figura 1: Modelo de Escala dos Graus de Participação

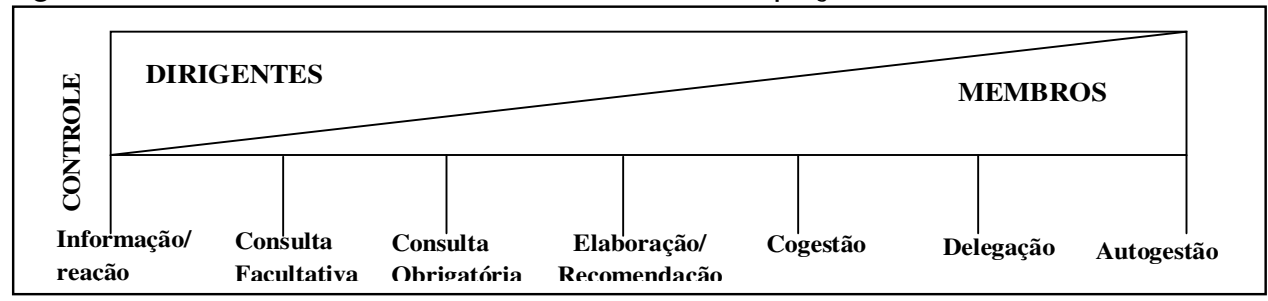

Fonte: Bordenave (2008, p. 31).

Os graus de participação são considerados do menor para os de maior complexidade e controle. Esses graus de participação demonstram de que forma as decisões de determinadas organizações são resolvidas. Inicia, portanto, pelo que considera o menor grau de participação: Informação/Reação - os dirigentes informam os membros da organização sobre decisões já tomadas; Consulta Facultativa - a administração pode, se quiser e quando quiser, consultar os subordinados, solicitando críticas, sugestões ou dados para resolver o problema; Consulta Obrigatória - os subordinados são consultados em determinadas situações embora a decisão final pertença ao superior; Elaboração/Recomendação - os subordinados elaboram propostas e 
recomendam medidas que a administração aceita ou rejeita mediante justificativa; Cogestão - a administração da organização é compartilhada por um colegiado; Delegação - os administrados tem autonomia em certos campos ou jurisdição de acordo com regras definidas previamente e em consenso; Autogestão - o grupo define seus objetivos, escolhe os meios e estabelece os controles necessários e a liderança é compartilhada (BORDENAVE, 2008; p. 31-32). O autor (2008) afirma que todos os princípios de participação devem ser vistos e entendidos dentro do processo geral, histórico e de construção de uma sociedade na qual todos os seus membros tenham parte na gestão e controle dos processos produtivos e parte equitativa no usufruto dos benefícios advindos do seu trabalho e esforço.

\section{METODOLOGIA}

A metodologia foi uma abordagem quantitativa (MINAYO, 2007; LAKATOS et al, 1985), classificando-se como um estudo de caso e quanto aos objetivos e finalidades, caracterizando-se como uma pesquisa descritiva (GIL, 2008).

Considerando as 72 escolas de Ensino Fundamental da Rede Municipal de Ensino de Natal/RN, em que todas possuem Conselhos Escolares (CE), definiu-se pelo critério de tipicidade ou intencional, uma amostra de 22 (vinte e dois) Conselhos, que correspondem a 30\% dos CE existentes. Todos os segmentos das escolas foram representados pelos membros dos CE, totalizando 110 pesquisados. Os segmentos Professor e Técnico têm o maior número de pesquisados (100\%), perfazendo um total de 44 membros respondentes. No segmento Diretor, dos 22 pesquisados, dois representantes não responderam o questionário. No segmento Pais/Mães, apenas 15 membros $(68 \%)$ responderam ao instrumento de pesquisa, uma vez que os demais representantes não foram localizados, constando apenas o nome como membros do Conselho Escolar. Os Alunos apresentaram o menor número de respondentes, 13 59\%, 13 alunos. Isso aconteceu em razão de $41 \%$ das escolas pesquisadas só atuarem nos anos iniciais do Ensino fundamental e os alunos terem menos de 12 anos, o que, inviabiliza a participação dos mesmos nos Conselhos Escolares. 
O instrumento de coleta de dados utilizado foi um questionário, com questões fechadas, adaptado de Holanda (2007), onde estão identificados os graus de participação que podem ser alcançados nas organizações, do ponto de vista do menor ou maior acesso ao controle das decisões pelos membros. Composto por 13 perguntas, constituído por uma tabela de três colunas, sendo que na primeira estão as varáveis: Planejamento, execução e usufruto. $\mathrm{Na}$ segunda coluna estão as afirmativas, a partir dos indicadores de cada variável, com opções de 1 a 7 , em que o respondente registra sua percepção de acordo com os níveis da escala de graduação em que ficaram agrupados, conforme descrito a seguir: (1) Informação/reação; (2) Consulta Facultativa; (3) Consulta Obrigatória; (4) Elaboração/ Recomendação; (5) Cogestão; (6) Delegação; (7) Autogestão. Como forma de operacionalizar as questões de pesquisa e os respectivos objetivos, foram definidas as variáveis e seus indicadores, conforme demonstra o quadro 2 :

Quadro 2: As variáveis e seus indicadores

\begin{tabular}{|c|c|c|}
\hline Objetivos Específicos & Categorias & Indicadores/Questões \\
\hline $\begin{array}{l}\text { Conhecer o nível de participação } \\
\text { dos membros do Conselho Escolar } \\
\text { no planejamento do processo de } \\
\text { gestão educacional das escolas de } \\
\text { ensino fundamental da Rede } \\
\text { Municipal de Natal. }\end{array}$ & Planejamento & $\begin{array}{l}\text { 1.Participação da Elaboração do } \\
\text { Regimento Interno do Conselho da Escola } \\
\text { 2.Participação da Elaboração do } \\
\text { Regimento Interno da Escola } \\
\text { 3.Elaboração do Projeto Político } \\
\text { Pedagógico; } \\
\text { 4.Elaboração de plano de formação } \\
\text { continuada dos Conselheiros; } \\
5 \text { - Eleições para Diretor. }\end{array}$ \\
\hline $\begin{array}{l}\text { Identificar o nível de participação } \\
\text { dos membros do Conselho Escolar } \\
\text { na execução das atividades } \\
\text { educacionais das escolas de } \\
\text { ensino fundamental da Rede } \\
\text { Municipal; }\end{array}$ & Execução & $\begin{array}{l}\text { 6.Participação da comunidade escolar e } \\
\text { local; } \\
\text { 7.Participação com autonomia nas } \\
\text { deliberações de responsabilidade do } \\
\text { Conselho Escolar; } \\
\text { 8.Participo das decisões do Conselho em } \\
\text { igualdade de condições; } \\
\text { 9.Participo do processo de informações de } \\
\text { modo democrático e constante }\end{array}$ \\
\hline $\begin{array}{l}\text { Identificar o nível de participação } \\
\text { dos membros do Conselho Escolar } \\
\text { no usufruto produzido pelas } \\
\text { escolas de ensino fundamental da } \\
\text { Rede Municipal. }\end{array}$ & Usufruto & $\begin{array}{l}\text { 10. Usufruto do espaço físico da escola } \\
\text { 11. Usufruto do conhecimento produzido } \\
\text { pela escola } \\
\text { 12. Usufruto / Participo de programas / } \\
\text { cursos de formação continuada } \\
\text { 13. Responsabilidade pelos resultados } \\
\text { obtidos pela escola, como um todo. }\end{array}$ \\
\hline
\end{tabular}

Fonte: Dados da Pesquisa (2012). 


\section{RESULTADOS}

Com relação à participação dos Conselhos Escolares (CE) verificouse que na Dimensão PLANEJAMENTO, os dados mostram que nos indicadores Elaboração do Regime Interno do Conselho Escolar; Elaboração do Regime Interno da Escola; Participação na Elaboração do Projeto Político Pedagógico e Elaboração dos Planos de Formação Continuada dos Conselheiros, os respondentes percebem sua participação nos Graus mais elevados, ou seja, na Autogestão e Delegação. Na elaboração do Regimento Interno do Conselho Escolar, que define ações importantes, como calendário de reuniões, substituição de Conselheiros, condições de participação do suplente, processos de tomada de decisões, indicação das funções do Conselho, entre outras importantes atribuições, a participação não é igualitária. As decisões são tomadas pela equipe gestora.

O indicador "Participação nas Eleições para Diretor" registra o maior índice de participação dos membros dos CE. Torna-se relevante acrescentar que a eleição não significa a certeza de uma gestão participativa. Lück (2009) afirma que não é a eleição em si, como evento, que democratiza, mas sim o que ela representaria como parte de um processo participativo global, em que corresponderia apenas parte ou mesmo a culminância de um processo construtivo e significativo para a escola. Não há, segundo a autora, resultados significantes e consistentes que demonstrem a efetividade da eleição para as direções na prática democrática e construção da autonomia na gestão da escola. Diante disto, Souza (2006), afirma que parte dos educadores dos sistemas de ensino apontam os concursos públicos como tentativa de mudança, alegando que desta forma o diretor estaria menos submisso às variantes políticas da escola e do sistema de ensino. Torna-se importante destacar, sobre o Projeto Político Pedagógico, que, sendo o documento norteador de todas as ações da escola, haveria uma maior participação dos membros CE na sua elaboração, assim como deveria ser vivenciado por todos os envolvidos no processo educativo escolar. Deste modo, o índice de participação nos Graus menos elevados na sua elaboração pode ser considerado alto. 
Observa-se ainda, no que diz respeito à Participação na Elaboração do Plano de Formação Continuada dos Conselheiros 17,77\% afirmam não existir esta prática na escola.

Com referência a dimensão EXECUÇÃO há a percepção de participação nos Graus mais altos: 7-Autogestão, 6-Delegação e 5-Cogestão, em todas as dimensões, sendo o maior índice na Participação com Autonomia nas Deliberações de Responsabilidade do Conselho Escolar (74,43\%), seguido da Participação nas Decisões do Conselho Escolar em Igualdade de Condições $(71,10 \%)$. Percebe-se ainda um aumento na participação da Comunidade Local e Escolar. Creditam-se estes resultados ao fato de a comunidade, geralmente, habitar o seu entorno. Poucos participantes se avaliam nos Graus mais baixos, como por exemplo, na Elaboração/Recomendação, Consulta Obrigatória, Informação/Reação.

Neste contexto, considera-se a opinião de Sá (2004), quando afirma que as famílias querem participar da escola, e que os alunos também desejam que suas famílias estejam mais próximas a ela, assim como os dirigentes e professores também compartilham dessas concepções. Souza (2006), porém, observa um problema maior: a compreensão do que é participar, do que significa realmente ser parte da escola, questionando até que ponto a participação dos pais e alunos na definição e avaliação dos rumos da escola é bem aceita pelos professores e dirigentes.

Percebe-se, então, que a gestão da escola pública não é apenas tomar decisões. Implica, segundo Souza (2006), em identificar problemas, acompanhar ações, controlar, fiscalizar e avaliar resultados. Isso pressupõe a ampliação da participação das pessoas, o que significa que a participação não pode se resumir aos processos de tomada de decisões, o que só se efetiva quando as pessoas chamadas a participar são colocadas em condições adequadas para tal. Não se torna possível avaliar o trabalho desenvolvido na escola se não se tem acesso às informações que lhe permitam produzir tal avaliação.

A dimensão USUFRUTO foi relacionada ao usufruto dos benefícios e serviços gerados pela escola, bem como da participação, considerando os direitos e deveres dos envolvidos no processo, contemplando os indicadores: Usufruto do Espaço Físico da Escola, Usufruto do Conhecimento Produzido 
pela Escola, Participação em Programas e Cursos de Formação Continuada, Responsabilidade pelos resultados da Escola, como um todo.

A análise dos dados permite, ainda, constatar que existe uma convergência em todos indicadores na dimensão Usufruto, uma vez que acima da metade dos pesquisados se avaliam, em todos os segmentos, em Graus mais elevados de participação (7-Autogestão, 6-Delegação, 5-Cogestão). O maior índice encontra-se na Dimensão Responsabilidade Pelos Resultados Obtidos Pela Escola Como um Todo (74,44\%) seguido do Usufruto do Espaço Físico da Escola (73,33\%) e Participação no Conhecimento Produzido Pela Escola (72,21\%). Nas demais Dimensões os pesquisados se avaliam em Graus menos elevados de Participação, como: 4-Elaboração/Recomendação, 3Consulta Obrigatória, 2- Consulta Facultativa e 1- Informação/Reação. Constata-se, através dos dados, que existe uma percepção, por parte dos pesquisados, de participação em Graus mais altos, no Usufruto. Torna-se importante ressaltar ainda, a participação na dimensão: Conhecimento Produzido pela Escola, considerando que a escola pública, em todos os níveis e modalidades da Educação Básica, tem como função social formar o cidadão, através da construção do conhecimento, sendo indispensável que socialize o conhecimento, fazendo com que seja criticamente apropriado, tanto pelos estudantes como pela comunidade local, o que representa, de fato, um elemento determinante para o processo de democratização tanto da escola como da sociedade, em geral.

\section{CONSIDERAÇÕES FINAIS}

Constatou-se, por meio dos dados demonstrados, que os objetivos foram atingidos, uma vez que os membros dos Conselhos Escolares estudados neste trabalho revelaram, em suas respostas constantes no instrumental de pesquisa, em que grau percebem a sua participação na gestão das escolas, segundo as dimensões Planejamento, Execução e Usufruto.

Embora tenha sido comprovada, em termos gerais, que existe uma percepção de participação em graus mais elevados por parte dos segmentos pesquisados, evidencia-se, ao mesmo tempo, uma discrepância em relação aos resultados, em todas as variáveis, entre os segmentos administrativos e a 
comunidade escolar: Pais/Mães e Alunos. Creditam-se este resultado ao fato de que, dentre os pesquisados, o maior número de participantes foram os técnicos, professores e diretores, ou seja, quem já está envolvido no processo de gestão. Essa diferença de percepção sugere a necessidade de estratégias e instrumentos que possibilitem a efetiva participação de todos os segmentos dos Conselhos, tanto no que se refere ao planejamento quanto à execução e usufruto dos bens produzidos pela escola, rumo à consolidação de uma gestão efetivamente participativa.

Isso significa, a guisa de sugestões, a necessidade de que se promovam ações para a descentralização, no sentido de reduzir a desigualdade de participação entre os segmentos dos CE, promovendo uma maior integração entre eles, assim como o investimento na capacitação dos Conselheiros, de modo que tenham conhecimento do significado da importância dos Conselhos Escolares como órgãos colegiados, representantes de toda uma comunidade, conscientizando-os da importância efetiva de sua participação, tanto no que se refere à elaboração, execução quanto ao usufruto dos bens produzidos pela escola.

\section{REFERÊNCIAS}

AMMANN, Safira Bezerra. Participação Social. São Paulo: Cortez \& Moraes Ltda, 1977.

BORDENAVE, Juan E.Díaz. O que é Participação. São Paulo: Brasiliense, 2008.

BRASIL. Programa Nacional de Fortalecimento dos Conselhos Escolares. Conselho Escolar e o financiamento da educação no Brasil. Caderno 1. Brasília: MEC, SEB, 2006.

CURY, Carlos. Roberto. Jamil. Gestão democrática da educação: Exigências e Desafios, In: Revista Brasileira de Política e Administração da Educação, ANPAE, v. 18, no 2, p. 153-297 (jul/dez). São Bernardo do Campo, São Paulo, 2002.

FARIA, José Henrique de. Gestão Participativa: Relações de Poder e de Trabalho nas Organizações. São Paulo: Atlas, 2009.

GIL, Antônio Carlos. Métodos e Técnicas de Pesquisa Social. São Paulo: Atlas, 2008. 
HOLANDA, Francisco Carlos Bandeira. Educação Descentralizada: A Participação dos Profissionais da Educação nos Processos de Gestão da Regional V do Município de Fortaleza. 2007. 124 f. Dissertação (Mestrado em Educação). Fortaleza: Universidade Estadual do Ceará, 2007.

JOHANN, Sílvio Luiz. O Modelo Brasileiro de Gestão Organizacional: Análise das Ideias. São Leopoldo: UNISINOS, 1996.

LAKATOS, Eva M.; MARCONI, Marina de A. Fundamentos de Metodologia Científica São Paulo: Atlas, 1985.

LÜCK, Heloísa. Concepções e Processos Democráticos de Gestão Educacional. Série Cadernos de Gestão, v. II. Petrópolis. RJ: Vozes, 2009.

MINAYO Maria Cecilia. O desafio do conhecimento: pesquisa qualitativa em saúde. Rio de Janeiro: Abrasco; 2007.

MOTTA, Paulo R. Gestão contemporânea: a ciência e a arte de ser dirigente. Rio de Janeiro: Record, 1999.

PINTO, Miguel Luiz Marun; COSTA, Miriam Brum da Silva. Gestão Participativa: A Trajetória no Brasil. Revista Pensamento Contemporâneo em Administração, Rio de Janeiro, v. 3 n. 1, jan./abr. 2009 - 36-46. ISSN 19822596. Disponível em: <http://www.uff.br/pca/index.php/pca/issue/view/17>. Acesso em: 20 jun.2012.

SÁ, Maria C. A. C. 2004. Políticas educacionais e o grêmio estudantil em escolas públicas municipais da cidade de São Paulo. Dissertação de Mestrado (Administração, Comunicação e Educação). Santos: USM.

SOUZA, Ângelo Ricardo de. Perfil da Gestão Escolar no Brasil. 294 f. Tese (Doutorado em Educação: História, Política, Sociedade). São Paulo: Pontifícia Universidade Católica de São Paulo, 2006. Disponível em: <http://www.nupe.ufpr.br/angelotese.pdf>. Acesso em: 15 Jun. 2012.

\footnotetext{
${ }^{1}$ Lydia Maria Pinto Brito - lydiabrito@unp.br - Doutora - Professora do Mestrado em Administração - Universidade Potiguar - UnP- (Orientadora)

${ }^{2}$ Regina Lúcia Maciel de Sousa - remaciel@unp.br - Mestre - Professora de Graduação e Pós-Graduação presencial, EaD e Graduação Executiva - Escola de Educação - Universidade Potiguar - (Autora)

${ }^{3}$ Fernanda Fernandes Gurgel - fernandafgurgel@hotmail.com - Doutora - Professora do Mestrado em Administração - Universidade Potiguar - UnP- (Co-Orientadora)
}

RECEBIDO EM: novembro/2014

APROVADO EM: dezembro/2014 